\title{
Relationship between lipid profile blood and thyroid hormones in patient with type 2 diabetes mellitus
}

\begin{abstract}
Background: Diabetes and thyroid dysfunction are commonly associated, there are few studies have actually assessed this association in type 2 diabetes mellitus (T2DM). Objective: The current study was to examine the relationship between blood lipids profile and thyroid hormones in T2DM.
\end{abstract}

Material and methods: The study population comprised 160 obese T2DM patients, the mean age was $49.28 \pm 6.17$ year and mean body mass index was $33.52 \pm 4.11 \mathrm{~kg} / \mathrm{m} 2$ and have been with diabetes above five years were included. In the other hand, 160 age and sex matched non-diabetes study subjects who were with the diabetes patients at the time of the data collection participated in the study as a control group, the mean age was $48.12 \pm 7.35$ year and mean body mass index was $31.74 \pm 3.82 \mathrm{~kg} / \mathrm{m} 2$.

Results: The biochemical characteristics of the T2DM group and the non-diabetic group, showed that T2DM study subjects had a significant higher serum TC, LDL-C and TG than non-diabetic subjects. However, T2DM study subjects had a significant lower serum HDL-C than non-diabetics. Moreover, significant lower T3 and T4; and higher TSH were observed among T2DM than non-diabetic subjects $(\mathrm{P}<0.05)$. In addition, there were significant positive correlations between TSH and TC, LDL-C and TG, and negative correlations between TSH and HDL-C of T2DM study subjects and non-diabetic subjects. Furthermore, there were significant negative correlations between T4 \& T3 and TC, LDL-C and TG, and positive correlations between T4 \& T3 and HDL-C of T2DM study subjects and non-diabetic subjects $(\mathrm{P}<0.05)$.

Conclusion: Low thyroid function was positively associated with a lipid dysregulation in patient with type 2 diabetes mellitus, so that we recommend thyroid screening which is essential to detect subclinical or clinical hypothyroidism among diabetics.

Keywords: blood lipids profile, non-insulin dependent diabetes mellitus, thyroid hormones
Volume 6 Issue 6 - 2017

\author{
Essam H jiffri \\ Department of Medical Laboratory Technology, King Abdulaziz \\ University, Saudi Arabia
}

\begin{abstract}
Correspondence: Essam H jiffri, Department of Medical Laboratory Technology, Faculty of Applied Medical Sciences, King Abdulaziz University, P.O. Box 80324, Jeddah, 21589, Saudi Arabia, Email ejiff@hotmail.com
\end{abstract}

Received: May 04, 2017 | Published: June 05, 2017

\section{Introduction}

Type 2 diabetes mellitus (T2DM) is most commonly current metabolic disorder as it affects more than 385 million and it is expected to reach about 590 million by 2035 worldwide. ${ }^{1}$ Type 2 diabetes mellitus is usually associated with dyslipidemia, which increase the risk of cardiovascular disorders. ${ }^{2,3}$

Thyroid dysfunction is a common endocrinal disorder in the general populations. ${ }^{4}$ The prevalence rate of thyroid dysfunction is much higher among diabetic population and estimated to be from $6.9 \%$ to $16 \% .^{5,6}$ Decreased thyroid function often accompanied with the elevation of total cholesterol (TC) and $4-14 \%$ of hypercholesterolemia was reported as a hypothyroid state. ${ }^{7-9}$ Moreover, cardiovascular disorders usually associated with thyroid dysfunction. ${ }^{10-12}$ Dyslipidemia and atherosclerosis related cardiovascular disorders were proved to be associated with hypothyroidism. ${ }^{13-16}$ Sinus tachycardia, atrial flutter and atrial fibrillation are commonly found in patients suffering from overt or subclinical hyperthyroidism. ${ }^{17}$ Currently, many studies stated that even with relative low thyroid functions which were commonly remain within normal range might be more dangerous in diabetics. ${ }^{18,19}$

Generally, no study in Saudi Arabia showing the association between thyroid hormone and dyslipidemia in diabetic and nondiabetic population while the prevalence and complication of diabetes are increasing rapidly in the country. ${ }^{20-23}$ Thus, knowing the association of thyroid hormone parameters with dyslipidemia among T2DM patients in the study area is profoundly important to enhance the knowledge gap of the interrelation between diabetes, thyroid hormone and dyslipidemia. Therefore, the aim of the present study was to examine the relationship between blood lipids profile and thyroid hormones in T2DM.

\section{Material and methods}

\section{Subjects}

The study population comprised 160 obese T2DM patients visiting king Abdulaziz University Hospital, Jeddah, Saudi Arabia, were randomly included in this study, the mean age was $49.28 \pm 6.17$ year and mean body mass index was $33.52 \pm 4.11 \mathrm{~kg} / \mathrm{m}^{2}$ and have been with diabetes above five years were included. Initially, a physician at King Abdulaziz University Hospital examined all participants; their medical history was taken to collect information about general condition, physical activity and current medications if any. Study participants were excluded from the study if they had a history of thyroid diseases, kidney, chronic liver and cardiovascular disorders, psychiatric disorder, administration of drugs affecting levels of thyroid hormone, pregnancy and lactation, subjects in antidepressant and/or antipsychotic therapy, HIV/AIDS patients, malignancy and type I diabetes mellitus. 
In the other hand, 160 age and sex matched non-diabetes study subjects who were with the diabetes patients at the time of the data collection participated in the study as a control group, the mean age was $48.12 \pm 7.35$ year and mean body mass index was $31.74 \pm 3.82 \mathrm{~kg} /$ $\mathrm{m}^{2}$. Demographic (age and sex) and anthropometric (height, weight, body mass index (BMI)) data were collected from all study subjects through structured questionnaire. Any contradictions in the questionnaire completion have consulted the interviewer for clarification. All hormone measurements and biomarker analyses were blinded and conducted in batches. The original sample of the T2DM enrolled in the study was 194 participants who underwent the eligibility assessment. In the enrollment phase, 14 of them were excluded as they didn't meet inclusion criteria and 5 refused to participate, then the randomization was done. During the follow up, 7 patients discontinued intervention (5 patients had work related schedule problems and 2 patient discontinued due to unknown reason). In addition, 8 patients were excluded from the analysis due to insufficient blood sample. The Ethics Committee of the Faculty of Applied Medical Sciences, King Abdulaziz University, approved this study. All participants signed a written informed consent.

\section{Measurements}

In all subjects, independent assessors were blinded to group assignment and not involved in the routine treatment of the participants performed clinical evaluations and laboratory analysis. Body mass index (BMI) was calculated on the basis of weight (kilograms) and height (meters), and subjects were classified as normal weight (BMI $18.5-24.9 \mathrm{~kg} / \mathrm{m}^{2}$ ), overweight (BMI $25-29.9 \mathrm{~kg} / \mathrm{m}^{2}$ ), and obese (BMI $\geq 30 \mathrm{~kg} / \mathrm{m}^{2}$ ). In addition, between 07:30 and 09:00, after an overnight fast of 12hour fasting blood sample was drawn. The blood sample in EDTA.K3 containing tubes was used for fasting plasma glucose (FBG) determination. FBG were analyzed by automated chemistry analyzer (ABX Pentra 400, France) through hexokinase method. Blood sample in the plain vacutainer tube was allowed to clot and centrifuged at $3000 \mathrm{rpm}$ for $10 \mathrm{~min}$ to separate the serum from the whole blood for lipid profile and thyroid hormone function test. Blood lipid profile included Triglycerides (TG), high-density lipoprotein cholesterol (HDL-c), low-density lipoprotein cholesterol (LDL-c) and Total blood cholesterol (TC) were measured by enzymatic determination method (ABX Pentra 400, France). Thyroid hormone function test was measured by enzyme-linked immunoassay sandwich method with a final fluorescent detection (VIDAS, biomeriux SA, France). The test included Thyroid Stimulating Hormone (TSH), Triiodothyronine (T3) and Tetraiodothyronine (T4).

\section{Statistical analysis}

SPSS (Chicago, IL, USA) version 21 was used for statistical analysis of data. Quantitative variables were described as mean \pm SD. An independent t-test was used to compare mean values of each parameter among the groups. To observe possible relationships between parameters, Pearson's correlation coefficient (r) was used. All assumptions were carefully appreciated in each model we followed. All variables with p- value less than 0.05 were considered as statistical significance.

\section{Results}

The anthropometric and baseline data of the whole study participants are shown in Table 1. The mean age of the no-diabetic control group was $48.12 \pm 7.35$ year, where the mean age of the T2DM group was $49.28 \pm 6.17$ year. Comparison between both groups regarding baseline variables showed that: there was no statistically significant difference between both groups as regards age, gender, BMI, urea, albumin, systolic blood pressure and diastolic blood pressure (respectively; $\mathrm{P}=0.57, \mathrm{P}=0.62, \mathrm{P}=0.48, \mathrm{P}=0.61, \mathrm{P}=0.78$, $\mathrm{P}=0.53$ and $\mathrm{P}=0.82$ ). Regards the HbAlc, it was found to be more in the T2DM group than in the non-diabetic group $(\mathrm{p}=0.014)$. In addition, the raised FBS level was found to be more in the T2DM group than in the non-diabetic group with a statistically significant difference between the two groups $(\mathrm{p}=0.018)$. When comparing the PPS between the two groups, PPS level showed a statistical significant difference $(\mathrm{p}=0.025)$, (Table 1$)$.

Table I Descriptive study on the anthropometric and baseline data of study participants

\begin{tabular}{llll}
\hline Variable & Group (A) (T2DM) & Group (B) (Non-Diabetic) & Significance \\
\hline Age & $49.28 \pm 6.17$ & $48.12 \pm 7.35$ & $\mathrm{P}>0.05$ \\
Sex (Male: Female) & $56(35 \%): 104(65 \%)$ & $44(27 \%): 116(73 \%)$ & $\mathrm{P}>0.05$ \\
BMI $(\mathrm{kg} / \mathrm{m} 2)$ & $33.52 \pm 4.11$ & $31.74 \pm 3.82$ & $\mathrm{P}>0.05$ \\
Urea $(\mathrm{mg} / \mathrm{dL})$ & $31.87 \pm 5.19$ & $30.62 \pm 4.76$ & $\mathrm{P}>0.05$ \\
Albumin $(\mathrm{mg} / \mathrm{dL})$ & $4.38 \pm 0.82$ & $4.65 \pm 0.91$ & $\mathrm{P}>0.05$ \\
SBP $(\mathrm{mm} \mathrm{Hg})$ & $131.21 \pm 11.47$ & $127.42 \pm 8.25$ & $\mathrm{P}>0.05$ \\
DBP $(\mathrm{mm} \mathrm{Hg})$ & $82.13 \pm 5.22$ & $79.85 \pm 4.61$ & $\mathrm{P}>0.05$ \\
HbAlc $(\%)$ & $7.65 \pm 1.48 *$ & $5.23 \pm 0.97$ & $\mathrm{P}<0.05$ \\
FBS $(\mathrm{mg} / \mathrm{dl})$ & $185.24 \pm 31.24 *$ & $125.41 \pm 16.32$ & $\mathrm{P}<0.05$ \\
PPS $(\mathrm{mg} / \mathrm{dl})$ & $276.17 \pm 42.53^{*}$ & $168.78 \pm 29.46$ & $\mathrm{P}<0.05$ \\
\hline
\end{tabular}

$(*)$ indicates a significant difference between groups, $\mathrm{P}<0.05$.

BMI, body mass index; HBAIc, glycosylated hemoglobin; FBS, fasting blood sugar; PPS, postprandial blood sugar

Regarding the biochemical characteristics of the T2DM group and the non-diabetic group, Table 2 shows that T2DM study subjects had a significant higher serum TC, LDL-C and TG than non-diabetic subjects. However, T2DM study subjects had a significant lower serum HDL-C than non-diabetics. Moreover, significant $(\mathrm{P}<0.05)$ lower T3 and T4; and higher TSH were observed among T2DM than non-diabetic subjects $(\mathrm{P}<0.05)$. 
Table 2 Biochemical characteristics of T2DM and non-diabetes study participants

\begin{tabular}{llll}
\hline Variable & Group (A) (T2DM) & Group (B) (Non-Diabetic) & Significance \\
\hline T4 (pmol/l) & $11.25 \pm 3.28^{*}$ & $13.84 \pm 4.65$ & $\mathrm{P}<0.05$ \\
T3 (pmol/l) & $3.47 \pm 1.12^{*}$ & $4.61 \pm 1.23$ & $\mathrm{P}<0.05$ \\
TSH (mlU/ml) & $5.62 \pm 1.74^{*}$ & $3.85 \pm 1.31$ & $\mathrm{P}<0.05$ \\
TG $(\mathrm{mg} / \mathrm{dL})$ & $257.17 \pm 41.38^{*}$ & $179.45 \pm 32.16$ & $\mathrm{P}<0.05$ \\
HDL-c $(\mathrm{mg} / \mathrm{dl})$ & $37.15 \pm 9.24^{*}$ & $48.73 \pm 10.11$ & $\mathrm{P}<0.05$ \\
LDL-c (mg/d) & $186.21 \pm 37.53^{*}$ & $165.19 \pm 28.13$ & $\mathrm{P}<0.05$ \\
TC $(\mathrm{mg} / \mathrm{dL})$ & $271.55 \pm 46.29^{*}$ & $232.64 \pm 37.15$ & $\mathrm{P}<0.05$ \\
\hline
\end{tabular}

$\left.{ }^{*}\right)$ indicates a significant difference between groups, $\mathrm{P}<0.05$.

T4, thyroxine; T3, triiodothyronine; TSH, thyroid stimulating hormone; HDL-c, high-density lipoprotein cholesterol; LDL-c, low--density lipoprotein cholesterol; TC, total cholesterol;TG, triglycerides

In Pearson correlation test, Table 3 shows that there were significant positive correlations between TSH and TC, LDL-C and TG, and negative correlations between TSH and HDL-C of T2DM study subjects and non-diabetic subjects. Furthermore, there were

significant negative correlations between T4 \& T3 and TC, LDL-C and TG, and positive correlations between T4 \& T3 and HDL-C of T2DM study subjects and non-diabetic subjects $(\mathrm{P}<0.05)$.

Table 3 Pearson bivariate correlations between dependent variables (TSH,T3,T4) and studied variables (TG, HDL-c, LDL-c,TC) among T2DM and non-diabetes study participants

\begin{tabular}{lllllll}
\hline \multirow{2}{*}{ Tested parameters } & \multicolumn{2}{l}{ Group (A) (T2DM) } & \multicolumn{3}{l}{ Group (B) (Non-diabetic) } \\
\cline { 2 - 7 } & T4 (pmol/l) & T3 (pmol/l) & TSH (mlU/ml) & T4 (pmol/l) & T3 (pmol/l) & TSH (mIU/ml) \\
\hline TG (mg/dL) & $-0.532^{*}$ & $-0.726^{* *}$ & $0.584^{*}$ & $-0.514^{*}$ & $-0.53 I^{*}$ & $0.728^{* *}$ \\
HDL-c (mg/dl) & $0.615^{* *}$ & $0.528^{*}$ & $-0.522^{*}$ & $0.672^{* *}$ & $0.719^{* *}$ & $-0.538^{*}$ \\
LDL-c (mg/dl) & $-0.519^{*}$ & $-0.673^{* *}$ & $0.546^{*}$ & $-0.59 I^{*}$ & $-0.672^{* *}$ & $0.655^{* *}$ \\
TC $(\mathrm{mg} / \mathrm{dL})$ & $-0.622^{* *}$ & $-0.518^{*}$ & $0.632^{* *}$ & $-0.628^{*}$ & $-0.544^{*}$ & $0.512^{*}$
\end{tabular}

Spearman's correlation was used*: $\mathrm{P}<0.05^{* *}: \mathrm{P}<0.01$.

\section{Discussion}

Diabetes is an endocrine metabolic disorder and it is a major threat to the public health and a leading cause of morbidity and mortality worldwide. ${ }^{24}$ Thyroid dysfunction and T2DM are the most common endocrinal disorders in daily clinical practice, while the underlying mechanisms are not fully understood. ${ }^{25}$ There is an association between diabetes and thyroid dysfunction which have important clinical implications. ${ }^{26-28}$ Thyroid hormones are essential for lipid metabolism regulation ${ }^{29,30}$ and thyroid dysfunction is usually associated with dyslipidemia, ${ }^{31}$ in the other hand T2DM is associated with abnormal blood lipid profile. ${ }^{32}$ Several studies evaluated the relationship between thyroid hormones and lipid abnormalities, few have actually assessed this association in patients with T2DM. ${ }^{33,34}$

In the present study, higher serum level of TC, LDL-C and TG was found among T2DM patients than non-diabetic subjects. This might be from low activity of lipoprotein lipase enzyme or the limited lipoproteins clearance, thus lead to increased TC, LDL-C and TG levels in blood. ${ }^{35-37}$ The relationship between thyroid gland function and blood lipid profile has been proved in T2DM and nondiabetics. $^{38,39}$

Regarding thyroid hormones, the present study revealed that the serum level of T3, T4 was significantly lower in T2DM patients while serum level of TSH was significantly higher in T2DM patients when compared to that of non-diabetic subjects. The results of present study were in accordance with the reports of. ${ }^{40-44}$ However, Anveetha et al., ${ }^{45}$ reported that serum level of TSH and FBS were significantly increased among 30 patients with T2DM along with lower level of T3 and T4 than in healthy control subjects. Diabetes induced hypothalamopituitary-thyroid axis alterations that resulted in reduction in thyroid releasing hormone (TRH) synthesis and release that reduce iodide uptake by thyroid gland that limit T3 and T4 production. ${ }^{46,47}$

In the current study, a low thyroid function was positively associated with a lipid dysregulation in T2DM patients as there was a positive significant relationship between TSH and TG, LDL-C and TC in addition to negative significant correlation between TSH and HDL-C among hypothyroid T2DM study subjects. Our findings were in harmony with the report of Chubb et al., ${ }^{48} \&$ Zhang et al., ${ }^{49}$ demonstrated a negative significant correlation between serum HDL-C and TSH in T2DM study participants and non-diabetic subjects. The same work result has been described by several researchers. ${ }^{50-53}$ However, Giandalia et al., ${ }^{14}$ \& Triolo's et al..${ }^{54}$ stated that TSH was significantly associated with high triglycerides in T2DM that related to visceral obesity and high risk of atherosclerosis susceptibility in T2DM. Moreover, positive correlation between TSH and TG, TC\& LDL-c may be due to activation of autoimmune that is involved in lipoprotein production. ${ }^{55}$ 
Finally, in the current study, T3 and T4 were negatively correlated to serum TC, TG and LDL-c. Thyroid hormones (T3 and T4), especially T3 have been demonstrated to regulate LDL receptors by binding directly to thyroid hormone responsive elements (TREs) ${ }^{56}$ and controlling sterol regulatory element-binding protein. ${ }^{57}$ Thyroid hormone also involved in hepatic expression of hydroxymethyl glutaryl coenzyme Areductase, which enhance cholesterol synthesis. ${ }^{58}$ Thus, decreased thyroid hormones lead to reduced expression of LDL receptors and hepatic cholesterol synthesis, which may reduce cellular uptake and catabolism of LDL-C from circulation and finally result in increased levels of circulating TC. In the other hand, Spanoudi and colleagues stated that following administration of $50 \mu \mathrm{g}$ of $\mathrm{T} 4$ one time daily 8 weeks resulted in significant reduction in TSH, TC, LDL-c , TG and significant increase in HDL-c in euthyroid patients with T2DM.

The current study has important strengths and limitations. The major strength is the randomized controlled nature of the study. In the other hand, the major limitation is the small sample size in both groups may limit the possibility of generalization of the findings in the present study. Finally, within the limit of this study, low thyroid function was positively associated with a lipid dysregulation in patient with T2DM, so that we recommend thyroid screening which is essential to detect subclinical or clinical hypothyroidism among diabetics.

\section{Acknowledgements}

None.

\section{Conflict of interest}

The author declares no conflict of interest.

\section{References}

1. International Diabetes Federation. IDF Diabetes Atlas. 2014.

2. Snipelisky D, Ziajka P. Diabetes and hyperlipidemia: a direct quantitative analysis - a direct analysis of the effects of insulin resistance on lipid levels in relation to atherosclerotic coronary artery disease. World $J$ Cardiovasc Dis. 2012;02:20-25.

3. Vibha U, Chittranjan V, Gurdeep KB, et al. Thyroid Disorders in Patients of Type 2 Diabetes Mellitus. Indian J Clin Biochem. 2013;28(4):336341.

4. Kadiyala R, Peter R, Okosieme OE. Thyroid dysfunction in patients with diabetes: clinical implications and screening strategies. Int J Clin Pract 2010;64(8):1130-1139.

5. Patricia Wu. Thyroid disorders and diabetes. Recent Adv Endocrinol. 2014;18(1):966-999.

6. Al Wazzan H, Daban A, Askar El Shazly RM. Prevalence and associated factors of thyroid dysfunction among type 2 diabetic patients, Kuwait. Alex J Med. 2010;46(2):141-148.

7. Pearce EN. Update in lipid alterations in subclinical hypothyroidism. $J$ Clin Endocrinol Metab. 2012;97(2):326-333.

8. Ichiki T. Thyroid hormone and atherosclerosis. Vascul Pharmacol. 2010;52(3-4):151-156.

9. Rizos CV, Elisaf MS, Liberopoulos EN. Effects of thyroid dysfunction on lipid profile. Open Cardiovasc Med J. 2011;5:76-84.

10. Neto AM, Parisi MC, Tambascia MA, et al. Relationship of thyroid hormone levels and cardiovascular events in patients with type 2 diabetes. Endocrine. 2014;45(1):84-91.

11. Ichiki T. Thyroid hormone and vascular remodeling. J Atheroscler Thromb. 2015:266-275.
12. Garduño-Garcia Jde J, Alvirde-Garcia U, López-Carrasco G, et al. TSH and free thyroxine concentrations are associated with differing metabolic markers in euthyroid subjects. Eur J Endocrinol. 2010;163(2):273-278.

13. Triolo M, Kwakernaak AJ, Perton FG, et al. Low normal thyroid function enhances plasma cholesteryl ester transfer in type 2 diabetes mellitus. Atherosclerosis. 2013;228(2):466-471.

14. Van Tienhoven-Wind LJ, Dullaart RP. Low-normal thyroid function and the pathogenesis of common cardiometabolic disorders. Eur J Clin Invest. 2015;45(5):494-503.

15. Van Tienhoven Wind LJ, Dullaart RP. Low-normal thyroid function and novel cardiometabolic biomarkers. Nutrients. 2015;7(2):1352-1377.

16. Tribulova N, Knezl V, Shainberg A, et al. Thyroid hormones and cardiac arrhythmias. Vascul Pharmacol. 2010;52:102-12.

17. Giandalia A, Russo GT, Romeo EL, et al. Influence of high-norma serum TSH levels on major cardiovascular risk factors and Visceral Adiposity Index in euthyroid type 2 diabetic subjects. Endocrine. 2014;47(1):152-160.

18. Taneichi H, Sasai T, Ohara M, et al. Higher serum free triiodothyronine levels within the normal range are associated with metabolic syndrome components in type 2 diabetic subjects with euthyroidism. Tohoku J Exp Med. 2011;224(3):173-178.

19. Yoseph Cherinet Megerssa, Mistire Wolde Gebre, Samuel Kinde Birru, et al. Prevalence of undiagnosed diabetes mellitus and its risk factors in selected institutions at Bishoftu Town, East Shoa, Ethiopia. Diabetes Metab. 2013;11(2):222-227.

20. Lemba D Nshissoa, Angela Reesea, Bizu Gelayea, et al. Prevalence of hypertension and diabetes among ethiopian. Diabetes Metab Syndr. 2012;6(1):36-41.

21. Abebe SM, Berhane Y, Worku A, et al. Diabetes mellitus in North West Ethiopia: a community based study. BMC Public Health. 2014;14(1):118

22. Shaw JE, Sicree RA, Zimmet PZ. Global estimates of the prevalence of diabetes for 2010 and 2030. Diabetes Res Clin Pract. 2010;87(1):4-14.

23. Muhammad Shihabudheen K, Prasanth NV, Dilip C, et al. Assessment of risk factors among type 2 diabetic populations in South Malabar region of Kerala. Arch Appl Sci Res. 2010;2(4):313-323.

24. Duvnjak L. Insulin sensitivity modifies the relationship between thyroid function and lipid profile in euthyroid type 1 diabetic patients. Endocrine. 2012;42(1):139-145.

25. Peppa M, Koliaki C, Nikolopoulos P, et al. Skeletal muscle insulin resistance in endocrine disease. Biomed Res Int J Biomed Biotechnol. 2010;2010:527850.

26. Duntas LH, Orgiazzi J, Brabant G. The interface between thyroid and diabetes mellitus. Clin Endocrinol (Oxf). 2011;5(1):1-9.

27. Gurjeet S, Vikas G, Anu Kumar S, et al. Evaluation of Thyroid Dysfunction Among type 2 diabetic Punjabi Population. Adv Biores. 2011;2(2):3-9.

28. Jin T, Teng X. Update on lipid metabolism and thyroid disorders. $J$ Endocrinol Diabetes Obes. 2014;2(3):1043.

29. Roos A, Bakker SJL, Links TP, et al. Thyroid function is associated with components of the metabolic syndrome in euthyroid subjects. $J$ Clin Endocrinol Metab. 2007;92(2):491-496.

30. Schofield JD, Liu Y, Rayaz PR. Diabetes dyslipidemia. Diabetes Ther Springer Healthcare. 2016;7(2):203-219.

31. Lambadiari V, Mitrou P, Maratou E, et al. Thyroid hormones are positively associated with insulin resistance early in the development of type 2 diabetes. Endocrine. 2011;39(1):28-32. 
32. Strollo F, Carucci I, More MG, et al. Free triiodothyronine and cholesterol levels in euthyroid elderly T2DM patients. Int J Endocrinol. 2012;2012:420370.

33. Sjl B, Tp L, Rob G, et al. Thyroid function is associated with components of the metabolic syndrome in euthyroid subjects. $J$ Clin Endocrinol Metab. 2007;92(2):491-496.

34. Cappola AR, Ladenson PW. Hypothyroidism and atherosclerosis. J Clin Endocrinol Metab. 2003;88(6):2438-2444.

35. Lo A, Castro A, Casamitjana R, et al. Thyroid function is intrinsically linked to insulin sensitivity and endothelium-dependent vasodilation in healthy euthyroid subjects. J Clin Endocrinol Metab. 2006;91(9):33373343.

36. Chubb SAP, Davis WA, Davis TME. Interactions among thyroid function, insulin sensitivity, and serum lipid concentrations: the fremantle diabetes study. J Clin Endocrinol Metab. 2005;90(9):5317-5320.

37. Bakker SJL, Maaten JANCTER, Popp Snijders C, et al. The relationship between thyrotropin and low density lipoprotein cholesterol is modified by insulin sensitivity in healthy euthyroid subjects. $J$ Clin Endocrinol Metab. 2001;86(3):1206-1211.

38. Vinu V, Chitnis P, Gupta VK. Evaluation of thyroid dysfunction among type II diabetic patients. Int J Pharm Bio Sci. 2012;2(4):150-155.

39. Swamy RM, Kumar N, Srinivasa K, et al. Evaluation of hypothyroidism as a complication in Type 2 Diabetes Mellitus. Biomed Res. 2012;23(2):170-172.

40. Demitrost L, Ranabir S. Thyroid dysfunction in type 2 diabetes mellitus: A retrospective study. Indian J Endocr Metab. 2012;16:S334-S335.

41. Witting V, Bergis D, Sadet D, et al. Thyroid disease in insulin-treated patients with type 2 diabetes: a retrospective study. Thyroid Res. 2014;7(1):2.

42. Saeed W, Abd ElRahman S, Abdrabo A. Evaluation of Thyroid Function Test in Sudanese Patients with Type 2 Diabetes Mellitus. Journal of Medical and Biological Science Research. 2016;2(8):131-135.

43. Anveetha P, Rao K, Chittimoju V. Study of thyroid profile in patients with type 2 diabetes mellitus. International Journal of Pharmacy and Biological Sciences. 2015;5(1):24-30.

44. Pasupathi P, Bakthavathsalam G, Saravanan G, et al. Screening for Thyroid Dysfunction in the Diabetic/Non-Diabetic Population. Thyroid Science. 2008;3(8):CLS1-6.

45. Suzuki J, Nanno M, Gemma R, et al. The mechanism of thyroid hormone abnormalities in patients with diabetes mellitus. Nippon Niabunpi Gakki Zasshi. 1994;70(4):465-470.
46. Chubb SAP, Davis WA, Davis TME. Interactions among thyroid function, insulin sensitivity, and serum lipid concentrations: the fremantle diabetes study. J Clin Endocrinol Metab. 2005;90(9):5317-5320.

47. Zhang Y, Lu P, Zhang L, et al. Association between lipids profile and thyroid parameters in euthyroid diabetic subjects:a cross-sectional study. BMC Endocr Disord. 2015;15(1):1-5.

48. Åsvold BO, Vatten LJ, Nilsen TI, et al. The association between TSH within the reference range and serum lipid concentrations in a populationbased study. The HUNT Study. Eur J Endocrinol. 2007;156(2):181-186.

49. Walsh JP, Bremner AP, Bulsara MK, et al. Thyroid dysfunction and serum lipids: a community-based study. Clin Endocrinol (Oxf). 2005;63(6):670-675.

50. Witte $\mathrm{T}$, Ittermann $\mathrm{T}$, Thamm $\mathrm{M}$, et al. Association between serum thyroid-stimulating hormone levels and serum lipids in children and adolescents:a population-based study of german youth. JClin Endocrinol Metab. 2015;100(5):2090-2097.

51. Elena M, Mendoza P, Gardun JDJ, et al. TSH and free thyroxine concentrations are associated with differing metabolic markers in euthyroid subjects. Eur J Endocrinol. 2010;163(2):273-278.

52. Giandalia A, Russo GT, Romeo EL, et al. Influence of high-normal serum TSH levels on major cardiovascular risk factors and Visceral Adiposity Index in euthyroid type 2 diabetic subjects. Endocrine. 2014;47(1):152-160

53. Onat A, Dönmez I, Karadeniz Y, et al. Type-2 diabetes and coronary heart disease: common physiopathology, viewed from autoimmunity. Expert Rev Cardiovasc Ther. 2014;12(6):667-679.

54. Bakker O, Hudig F, Meijssen S, et al. Effects of triiodothyronine and amiodarone on the promoter of the human LDL receptor gene. Biochem Biophys Res Commun. 1998;249(2):517-521.

55. Lopez D, Socarrás JFA, Bedi M, et al. Activation of the hepatic LDL receptor promoter by thyroid hormone. Biochim Biophys Acta (BBA) Mol Cell Biol Lipids. 2007;1771(9):1216-1225.

56. Shin DJ, Osborne TF. Thyroid hormone regulation and cholesterol metabolism are connected through sterol regulatory element-binding protein-2 (SREBP-2). J Biol Chem. 2003;278(36):34114-34118.

57. Chen $\mathrm{Y}, \mathrm{Wu} \mathrm{X}, \mathrm{Wu} \mathrm{R}$, et al. Changes in profile of lipids and adipokines in patients with newly diagnosed hypothyroidism and hyperthyroidism. Scientific Reports. 2016:1-7.

58. Spanoudi F, Vassilatou E, Maratou E, et al. Short-term administration of a small thyroxine dose to euthyroid type 2 diabetic patients improves the fasting lipoprotein profile. Clinical Lipidology. 2017;2(1):1-6. 